\author{
ADRIANA SARA JASTRZĘBSKA \\ Akademia Techniczno-Humanistyczna w Bielsku-Białej \\ ajastrzebska@ath.bielsko.pl
}

\title{
TERRITORIOS DEL TRAUMA: TERRORISMOS Y NARRATIVA HISPANOAMERICANA ACTUAL
}

\begin{abstract}
Adriana Sara Jastrzębska, Territorios del trauma: terrorismos y narrativa hispanoamericana actual [The territories of trauma: Acts of terror and the modern Hispano-American narrative], Studia Romanica Posnaniensia, Adam Mickiewicz University Press, Poznań, vol. XLII/2: 2015, pp. 21-32. ISBN 978-83-232-2863-9. ISSN 0137-2475. eISSN 2084-4158. DOI: 10.14746/strop.2015.422.002

In Colombia and Central America, the subject of terrorism - or of the acts of terror - is inevitable in all the literature that aspires to reflect the socio-political reality. In the last few years it has been given an exceptional importance. Taking as the basis various examples of the modern Colombian and Central American narrative, the article presents distinct ways in which the novels try to deal with the trauma of the recent history. The analyzed works are Los ejércitos by E. Rosero, Insensatez by H. Castellanos Moya and El material humano by R. Rey Rosa. The analysis focuses on how the tragic experiences of the common people are absorbed by the narrative, turning trauma into literature. We are particularly interested in a meta-literary reflection regarding social commitment of literature, as well as the impossibility of dealing with trauma and the relations between the esthetic and ethical values in literary representations of trauma.
\end{abstract}

Key words: trauma; Colombia; violence; Central America; recent Spanish American narrative

\section{INTRODUCCIÓN}

La literatura de la violencia trata sobre los muertos, pero su objetivo son los vivos: de esta «paradoja» parte la búsqueda por parte de los autores latinoamericanos de una voz narrativa adecuada y de recursos artísticos eficaces que les permitan asumir y transformar en materia literaria las experiencias trágicas de los pueblos — sea el colombiano, afectado en los últimos sesenta años por violencias múltiples (violencia partidista, guerra de guerrillas, paramilitarismo, narcotráfico), sean los centroamericanos que siguen recuperándose tras varias décadas de conflicto interno- En la búsqueda de creación artística que persiguen los narradores se tiene en cuenta la tradición cultural de ambas regiones, que por lo general recurre a la creación de una literatura testimonial, por ello oscila entre un registro minucioso de los hechos violentos y los constructos metafóricos y simbólicos que le acompañan. La literatura colombiana y la centroamericana comparten igualmente una característica importante que ha influido bastante en el rumbo tomado por la narrativa de la vio- 
lencia: un hiato entre las élites cultas, de las cuales se reclutan los escritores, y la población más afectada por las violencias y/o traumas, que es la menos educada, analfabeta con frecuencia. El problema de dar cuenta de las experiencias sufridas por aquel grupo sería entonces el de hablar en nombre del Otro o concederle la palabra al mismo. Surgen inmediatamente las dudas acerca de la literatura como instrumento adecuado para curar traumas y denunciar los abusos en sociedades en que faltan lectores.

El objetivo del presente trabajo es reflexionar sobre las distintas maneras que propone la novela de enfrentarse con los traumas de la historia reciente, recurriendo a ejemplos provenientes de la narrativa actual colombiana y centroamericana. En el análisis de una selección de textos nos fijaremos en cómo la novela asume y absorbe las experiencias trágicas del pueblo y en cómo convierte el trauma en literatura. El corpus que va a ser analizado se compone de novelas bastante recientes, publicadas durante la primera década de 2000, todas de autores reconocidos no solo en sus respectivos países, sino también fuera de América Latina: Horacio Castellanos Moya, Rodrigo Rey Rosa y Evelio Rosero.

\section{NARRAR LO INENARRABLE: RELATO PERTURBADO(R)}

Según Cathy Caruth, el trauma nace a raíz de un evento tan horroroso y abrumador que no se deja insertar en los esquemas existentes de entendimiento ni en las cadenas asociativas de significado. Ya que el evento no se presencia plenamente en el momento de ocurrir, uno nunca acaba de entender qué pasó realmente (Caruth, 1995a: 4-5). Tal planteamiento pone de relieve la naturaleza indecible e inenarrable del trauma. A su vez, Dori Laub (1995: 64), subraya la importancia de dar testimonio, ya que «[t]he longer the story remains untold, the more distorted it becomes in the survivor's conception of it, so much so that the survivor doubts the reality of the actual events». De esta manera, el trauma se sitúa en las arenas movedizas entre la realidad y la irrealidad, la inconsciencia o incluso la ficción. Construir un relato sobre una experiencia traumática tendría entonces un inapreciable valor terapeútico, significaría una superación del trauma, un restablecimiento de la relación de la víctima con el mundo real y sería crucial para el proceso de curación, tanto a nivel individual, como histórico. No obstante, para Caruth (1995b: 153-154), un trauma convertido en narración, en relato, paradójicamente, pierde su precisión y fuerza, lo que para las víctimas puede constituir una suerte de sacrilegio a la verdad.

El enfrentamiento con un trauma se plantea entoces como un proceso doloroso, paradójico y, además, mayoritariamente condenado al fracaso. Las obras que se presentan a continuación parecen ilustrar el proceso de combate con un trauma. Dos novelas centroamericanas, Insensatez (2004) del salvadoreño Horacio Castellanos Moya y El material humano (2009) del gualtemalteco Rodrigo Rey Rosa, son dos 
intentos de aproximarse, a partir de un texto o conjunto de textos, al trauma debido a la violencia sufrida por varios pueblos indígenas en la segunda mitad del siglo XX. Aunque el nombre del país no se hace explícito, por varios indicios se puede suponer que se trata de Guatemala. Los narradores de ambas novelas bien pueden considerarse unos álter ego de los respectivos autores.

En Insensatez al narrador se le encarga un trabajo que consiste en corregir el estilo de un informe compuesto por varios testimonios de los indios cachiquel. La publicación de dicho informe y la consiguiente muerte no aclarada de su promotor principal corresponden a las circunstancias de la publicación del informe REMHI (Recuperación de la Memoria Histórica) Guatemala: Nunca Más en abril de 1998 y la muerte, dos días más tarde, de monseñor Juan José Gerardi. Leyendo y corrigiendo el informe, el narrador-protagonista descubre testimonios sobrecogedores que van afectando su salud mental hasta sumergirlo en el estado de insensatez evocado en el título y forzarlo a huir del país.

El material humano es un collage de textos de muy variada índole, cuyo centro es el relato sobre la investigación del narrador en un archivo y los cambios progresivos que se dan a raíz de esta actividad en su propia vida, las relaciones con su familia y amigos. Como en la novela de Castellanos Moya, con el tiempo sumergen al protagonista en una especie de pesadilla o incluso paranoia. Como textos secundarios aparecen apuntes del diario del protagonista, conversaciones con sus amigos y documentos transcritos sobre los abusos cometidos a la población indígena del país en varios momentos históricos.

Como vemos, los dos protagonistas se ven enfrentados a un trauma ajeno, van descubriendo experiencias del Otro que, progresivamente, se van colando en su propia vida. El testimonio de las víctimas se ve mediatizado por la actividad narrativa de ellos, y éstos, a su vez, poco a poco, se van traumatizando. Se sitúan en el segundo y el tercer nivel de testimonio; se convierten en testigos de testimonios ajenos y del proceso mismo de dar testimonio (Laub, 1995: 61). Cabe subrayar que, a nivel del peritexto, o sea lo que rodea el texto y orienta su lectura, ambas novelas niegan ser libros testimoniales. No obstante, las fórmulas usadas por ambos autores arrojan ciertas dudas dudas al respecto y, desde el principio, crean alguna tensión entre el declarado carácter ficcional de la obra y sus posibles correspondencias con un mundo extratextual. En la novela Insensatez, junto a los datos editoriales se puede leer: «Este es un libro de ficción. Nombres, personajes, lugares e incidentes son producto de la imaginación del autor o utilizados de manera ficticia. Cualquier parecido con personas reales, vivas o muertas, es una coincidencia» (Castellanos Moya, 2005: 4). La fórmula declara el carácter ficticio de la obra, pero al mismo tiempo sugiere que es probable una coincidencia con personas reales, lo que despierta dudas en lectores, seguros - hasta ese momento- de estar leyendo una obra de ficción. En Rey Rosa el juego con el lector mediante declaraciones va todavía más lejos. Al principio de El material humano se lee: «Aunque no lo parezca, aunque no quiera 
parecerlo, ésta es una obra de ficción» ${ }^{1}$ (Rey Rosa, 2009: 9). El autor guatemalteco se aleja de la fórmula estándar usada a efectos legales, usando palabras cargadas de emoción que ya plantean cierto tono de incredulidad. Al final del libro se ha puesto otra nota que parece negar el carácter puramente ficticio antes declarado: «Algunos personajes pidieron ser rebautizados» (Rey Rosa, 2009: 181). Como vemos, ambos autores usan elementos paratextuales para ubicar conscientemente sus obras en las arenas movedizas entre testimonio y ficción, para crear cierto ambiente de ambigüedad, reticencias y silenciamientos.

Como se ha dicho, El material humano es una suerte de collage que reúne textos muy variados. No obstante podemos distinguir claramente dos tipos o dos poéticas opuestas. Por un lado hay transcripciones de informes policiales, datos estadísticos, notas de prensa o comentarios de Internet, apuntes de los cursillos a los que el protagonista asiste. Se caracterizan por un número predominante de frases nominales, el uso de un lenguaje seco y científico, la mirada fría de un investigador: elementos que demuestran claramente la distancia entre el protagonista y su trabajo. Éstos se ven alternados con textos literarios, citas de escritores y filósofos, fragmentos del diario del protagonista en que reflexiona, comenta sus lecturas y sus sueños. Aquí predomina una reflexión intelectual sobre la naturaleza del mal y un surrealismo sofocante de miedos, fantasmas y paranoia. Conforme avanza su aventura con el archivo investigado, el segundo tipo de textos ocupa cada vez más espacio de la novela. La estrategia de enfrentar dos tipos de discurso permite ver la inmersión progresiva del protagonista -inconsciente solo al principio- en el mundo de la violencia y, al mismo tiempo, la ausencia de cualquier juicio ético por parte de éste sobre los hechos narrados. Rey Rosa —o su álter ego, el narrador de la novelaecha mano a palabras ajenas intentando comentar el terrorismo de Estado en Guatemala en clave literaria, oponiendo el sufrimiento de los indígenas, con frecuencia analfabetos y ajenos al mundo de la gran literatura mundial, a la reflexión intelectual de varios siglos sobre el mal y su existencia. El distanciamiento inicial del narrador pasa a ser un terror con tintes paranóicos y surrealistas que desemboca en una profunda impotencia creativa a la hora de formular sus propias reflexiones.

La heterogeneidad discursiva y el enfrentamiento de discursos resultan menos ostentosos en la novela Insensatez. No obstante, podemos verlos anunciados desde el inicio mismo del texto:

Yo no estoy completo de la mente, decía la frase que subrayé con el marcador amarillo, y que hasta pasé en limpio en mi libreta personal, porque no se trataba de cualquier frase [...] sino de la frase que más me impactó en la lectura realizada durante mi primer día de trabajo, de la frase que me dejó lelo en la primera incursión en esas mil cien cuartillas impresas casi a renglón seguido [...]. Yo no estoy completo de la mente, me repetí, impactado por el grado de perturbación mental en el que había sido hundido ese indígena cachiquel testigo del asesinato

\footnotetext{
${ }^{1}$ En este caso, la cursiva es de la autora del artículo.
} 
de su familia, por el hecho de que ese indígena fuera consciente del quebrantamiento de su aparato psíquico a causa de haber presenciado, herido e impotente, cómo los soldados del ejército de su país despedazaban a machetazos y con sorna a cada uno de sus cuatro pequeños hijos y enseguida arremetían contra su mujer, la pobre y en shock a causa de que también había sido obligada a presenciar cómo los soldados convertían a sus pequeños hijos en palpitantes trozos de carne humana. (Castellanos Moya, 2005: 13-14)

El fragmento expone la dinámica sobre la cual se construye la novela: la de convertir la oralidad de los testimonios indígenas en la palabra escrita del informe y, a través de la reescritura y la posterior relectura, transformar dichos testimonios en memoria histórica. Según Alexandra Ortiz Wallner (2012: 152) por medio de este procedimiento el narrador «cree encontrar el contacto más directo con el terror y el horror de genocidio». No obstante, a lo largo del relato se alternan el acercamiento a las masacres perpetradas contra los cachiqueles y el ostentoso distanciamiento. El protagonista se contagia de la insensatez de las víctimas (y los victimarios) o se distancia, recurriendo al sarcasmo, subrayando su fascinación puramente estética por las frases, así como su propia incongruencia frente a la experiencia traumática de los indígenas, actuando como un intelectual extranjero. El enfrentamiento de dos mundos distintos se ilustra muy bien en la escena que transcurre en un restaurante vegetariano en que se interfieren el discurso anti-carne, traumas por falta de duelo y el ambiente de sobremesa.

[...] Pilar inició su perorata en contra de la carne, que le parecía asquerosa y le causaba mucho daño, enumerando los diversos efectos nocivos y hasta mortales que la ingestión de carne producía, con un léxico y un énfasis propios de la hija de un médico franquista convertida en salvadora de indígenas, que eso hacía ella en sus viajes al interior del país, reunirse con las comunidades indígenas víctimas de las atrocidades militares para ayudarlas a superar sus traumas por la falta de duelo [...] procedí a sacar mi libreta de apuntes del bolsillo de mi americana de pana, para leerle unas estupendas frases sobre el tema que ella mencionaba, y la coloqué abierta sobre la mesa, junto a mi plato de sopa: Mis hijos dicen: mamá, mi pobre papá dónde habrá quedado, tal vez pasa el sol sobre sus huesos, tal vez pasa la lluvia y el aire, ¿dónde estará? Como que fuera un animal mi pobre papá. Esto es el dolor..., leí entre sorbos, y después busqué una frase que ese misma mañana me había electrizado: Los cerdos lo están comiendo, están repasando sus huesos..., pronuncié al tiempo que alcanzaba mi vaso de fresco de arrayán, que en ese restaurante no vendían cervezas, con el propósito de beber un trago que refrescara mi garganta para continuar con la lectura de la frase Quiero ver al menos los huesos, pero en ese instante me percaté de que Pilar no estaba disfrutando de mis frases [...] (Castellanos Moya, 2005: 47-48)

El fragmento parece una buena ilustración de lo que Dominick LaCapra dice sobre el trauma que consiste en un retorno repetitivo de un pasado reprimido, planteado como un estado de profunda confusión, una desarticulación de todas las distinciones y différance ilimitada (LaCapra, 2001: 21). En este caso, lo reprimido es el impacto por el contenido del informe; el protagonista sufre un trauma de segundo 
grado, una suerte de «meta-trauma» que progresivamente le traumatiza a él, devolviéndole imágenes sobrecogedoras en los momentos más inesperados.

Como se ha mencionado antes, en las dos novelas se hace énfasis en lo ajenos que son los dos narradores a los hechos y al mundo objeto de la investigación en que se ven involucrados. Dada la imposibilidad de identificarse con las víctimas a nivel consciente, observamos como el trauma de las víctimas se cuela en el inconsciente de los narradores, perturbando sus vidas y sus relatos. Ambos terminan al borde de la paranoia. La relectura cada vez más obsesiva de las frases del informe o el enfrentamiento de los datos del archivo con las bellas letras constituye una suerte de reflexión metalingüística, metadiscursiva y metapoética que pone al descubierto la impotencia de los intelectuales ante el trauma del pueblo indígena. En los dos casos, el relato refleja el proceso ineficaz de intentar insertar el trauma en las cadenas asociativas de significado de que habla Caruth, subrayando el carácter disruptivo de la experiencia traumática y la incapacidad de narrar el trauma, tanto el propio, como el ajeno. La distancia entre los testimonios de las víctimas y los que los leen o investigan impide, por un lado, la transformación del trauma en un relato y, por otro, da origen a una experiencia traumática de los protagonistas.

Se declara también la impotencia de la literatura. Tanto en Insensatez como en El material humano aparecen reflexiones de índole metaliteraria. La novela de Rey Rosa puede leerse en clave autoficcional, como una narración «[...] sobre la posibilidad de acercarse a un núcleo de verdad, sobre la legitimidad del discurso histórico» (Jossa, 2013: 55) y sobre el fracaso de un escritor para narrar el trauma. Observemos algunos momentos de la evolución de la actitud del narrador frente al Archivo, llamado «objeto novelable». En una ocasión evoca las palabras del poeta polaco Adam Zagajewski: «Describir nuevas variedades del mal y del bien —he aquí la magna tarea del escritor [...] ¿Y si las nuevas variedades llegaran a obliterar las viejas ideas del mal y del bien- de lo que pueden ser o llegar a ser en la subjetividad de cada uno, lo uno y lo otro?» (Rey Rosa, 2009: 84). A estas alturas todavía se declara relativamente optimista acerca de la importancia de su trabajo: «Una intuición: que el producto de mi trabajo de escritor podría ayudar a que el público no especializado conozca el Proyecto de Recuperación del Archivo, y que la gente llegue a entender la importancia de un hallazgo como éste» (Rey Rosa, 2009: 87). Sin embargo, su aventura desemboca en un fracaso abiertamente declarado: «Como hallazgo, como Documento o Testimonio, la importancia del Archivo es innegable (aunque increíble y desgraciadamente hay quienes quisieran quitársela) y si no he podido novelarlo, como pensé que podría, es porque me han faltado suerte y fuerzas» (Rey Rosa, 2009: 169).

En Insensatez la reflexión meta- (o auto-) ficcional aparece teñida del sarcasmo característico de Castellanos Moya. Tras varios días de corrección del informe, al protagonista se le ocurre un proyecto literario: fantasea con escribir una novela que trate de «[...] las razones por las cuales el registrador civil de Totonicapán había 
preferido ser torturado y asesinado antes de entregar el libro de difuntos a sus verdugos» (Castellanos Moya, 2005: 73). Alude a la estética magicorrealista, proyectando que la novela sería narrada por el alma en pena del registrador muerto «en todo momento con las palmas de sus manos sin dedos apretando las dos mitades de su cabeza para mantener los sesos en su sitio» (Castellanos Moya, 2005: 73). El corrector pronto se arrepiente y concluye: «a nadie en su sano juicio le podría interesar ni escribir ni publicar ni leer otra novela más sobre indígenas asesinados» (Castellanos Moya, 2005: 74), negando por igual el valor informativo y terapéutico de la literatura, subrayando el desinterés del tema por parte del público y del mercado editorial y, hasta cierto punto, confirmando la observación de Caruth (1995b: 153) sobre el trauma que pierde su fuerza una vez convertido en historia.

Como vemos, ambos autores, al declararse — a nivel diegético - impotentes ante el horror del trauma que les ha sido revelado, y poniendo de manifiesto la imposibilidad o inutilidad de convertirla en literatura «desconociendo la postura omnisciente del narrador, $[\ldots]$ no ceden la palabra a los marginados a través de narradores femeninos, campesinos, indígenas etc., sino construyen una zona de memoria a través de palabras que no les pertenecen. Dejan un espacio estructural vacío [...]» (Jossa, 2013: 58).

Los elementos analizados, es decir, la borrosidad de la frontera ficcióntestimonio, la heterogeneidad de ambos textos y la reflexión metaliteraria, demuestran que el problema de la inadecuación de la lengua y de la falta de recursos adecuados de expresión no se ve reflejado en la diégesis, sino en el relato mismo, en los discursos que se enfrentan y cuestionan mutuamente, en la gramática narrativa del texto distorsionada. Traumas residentes en la (in)consciencia de las víctimas y de los investigadores repercuten en la organización del relato, que se vuelve perturbado $\mathrm{y}$, a la vez, perturbador.

\section{EN EL FUEGO CRUZADO: LOS EJÉRCITOS}

Mientras que las novelas anteriores relataban enfrentamientos a traumas ajenos producidos en el pasado, Los ejércitos (2007) de Evelio Rosero relata el proceso mismo de producción del trauma. Caruth (1995a: 8) y LaCapra (2008: 188) coinciden en que el trauma no se registra en el momento mismo del evento que lo produce, sino tras un período de latencia. La obra narra, desde la perspectiva y con la voz de un profesor jubilado, la vida de San José, un pueblo colombiano imaginario, afectado desde hace varias décadas por la guerra de guerrillas, el ejército nacional y los paramilitares. A diferencia de otras novelas analizadas, aquí el narrador-protagonista sí que forma parte de la comunidad-víctima de la violencia. Comparte con sus vecinos el sufrimiento y la vida diaria en el prolongado conflicto. La novela no aspira a la objetividad ni a ser representación fiel y completa de la guerra en Colombia, ni 
tampoco propone explicaciones sociales, psicológicas o políticas de la realidad narrada. La historia del anciano errante por el pueblo buscando en vano a su esposa desaparecida parece ilustrar la represión, latencia y regreso de la experiencia traumática, así como los mecanismos mentales y emocionales que anteceden las manifestaciones del trauma.

El profesor Ismael Pasos es un setentón, avergonzado de su propia vejez y aficionado a espiar y contemplar eróticamente a las mujeres del pueblo. En palabras de César Valencia Solanilla (2007: 298):

El profesor es protagonista, agonista, voyeur y flânneur, y a través suyo el lector percibe esa alternancia entre una realidad muy compleja, saturada de violencia, asesinatos, crueldades, secuestros, despojos, tomas armadas, combates, destrucción, corrupción, que son esos referentes ya casi banales en nuestro país, y una realidad íntima, subjetiva, mediada por la obsesión erótica y el disfrute de los sentidos, inseparable de la desolación y el desastre.

La novela de Rosero se construye a partir del contrapunto entre la violencia y el amor, configurándose en un relato que oscila entre Eros y Tanatos y demuestra la omnipresencia de una violencia que se ha convertido en correlato ineludible de la vida cotidiana y la historia personal de los protagonistas: en punto de referencia y elemento integrante de la identidad de los colombianos. Es un buen ejemplo de ello el recuerdo de cómo Ismael conoció a Otilia, su esposa. La vio por primera vez en una estación de autobuses, y, antes de que iniciara una conversación con ella, un sicario mató a tiros a un hombre que estaba sentado a su lado. El inicio del amor se mezcla en su recuerdo con el trauma de ser testigo ocular de un asesinato, y el profesor Pasos sigue «repitiéndolos, asociándolos, de una manera casi que absurda, en mi memoria: primero la muerte, después la desnudez» (Rosero, 2010: 24).

De manera parecida, casi todos los recuerdos vienen acompañados de un eco del conflicto armado. En otras ocasiones, la tensión entre la violencia y la pasión refleja la tensión entre lo colectivo y lo individual, o una lucha, sea o no consciente y deliberada, para que la guerra no domine la vida íntima de las personas. Un ejemplo irónico de esto sería el encuentro («celebración») anual en casa de un vecino desaparecido que se convierte en una fiesta con bailes, o bien en una pelea espectacular entre la esposa del hombre y su amante oficial (Rosero, 2010: 57-58). Tanto a nivel individual como colectivo, lo erótico, lo pasional se configura como instrumento para reprimir y mitigar las consecuencias de la violencia sufrida a diario.

En uno de los motivos cruciales de la trama de la novela - la desaparición de Otilia - confluyen el amor y la violencia: el trauma de Ismael se debe por igual a la estéril búsqueda de su amada esposa y a la creciente presencia de la guerra en el pueblo. A partir de este momento se diluye el tiempo de la historia, volviéndose la realidad cada vez más violenta y al mismo tiempo más borrosa, fantasmagórica. ${ }^{2} \mathrm{El}$

\footnotetext{
${ }^{2}$ Véase el análisis del cronotopo de la novela propuesto por Iván Vicente Padilla Chasing (2012).
} 
pueblo de San José por el que vagabundea Ismael, solo, abandonado, medio muerto y medio loco, hace pensar en la Comala de Juan Rulfo, poblada de fantasmas, o en el Macondo garciamarquiano en su fase apocalíptica. Se configura casi literalmente como un territorio del trauma donde los tiempos han hecho implosión.

Siendo víctima directa de la violencia, a diferencia de otros narradores de novelas comentadas en este artículo, el narrador de Los ejércitos coincide con los anteriores en cuestionar o incluso desarmar por completo los discursos oficiales acerca del conflicto armado. Al hacerlo desde una subjetividad radical, con una fuerte dosis de ironía, Ismael llega a crear su íntimo sistema ético, basado en el cuestionamiento o rechazo de los valores tradicionales. El profesor Pasos empieza rechazando la autoridad, situándose por encima de la misma. No trata en serio ni al dirigente civil ni al religioso: «Le enseñé a leer al que ahora es el alcalde, y al padre Albornoz; a ambos los tiré de las orejas, y ya ve, no me equivoqué: todavía deberíamos jalárselas» (Rosero, 2010: 16). Desprecia el papel de los medios de comunicación, convencido de su completa inutilidad y falta de importancia. Se niega a hablar con la periodista; el resultado del encuentro es una incomunicación ostentosa: «Ella y su camarógrafo se me antojan de otro mundo, ¿de qué mundo vienen? [...], quieren acabar pronto, se nota en sus ademanes, ella vuelve a decirme algo, ya no escucho, no quiero escuchar, [...] no quiero ni puedo hablar: doy un paso atrás, con un dedo me señalo la boca, una, dos, tres veces, indicándole que soy mudo» (Rosero, 2010: 135). También cuestiona explícitamente la solidaridad y compasión entre los vecinos, declarando en voz alta: «Yo también estoy algo conforme, te confieso, de que Marcos Saldarriaga haya desaparecido» (Rosero, 2010: 56).

Sin embargo, los discursos más cuestionados, explícita e implícitamente, son el religioso y el nacional. A lo largo de la obra el narrador pone al descubierto los vacíos semánticos de ambos.

[...] el padre Albornoz replica abriéndose de brazos, ¿qué puede saber él?, les habla como en sus sermones, y tal vez tiene razón, poniéndose en su lugar: el temor de resultar mal interpretado, de terminar acusado por este o ese ejército, $[\ldots]$ ha hecho de él un concierto de balbuceos [...]. (Rosero, 2010: 93-94)

[...] dicen que quieren comprar, para llevárselo de recuerdo, nuestro antiguo San Antonio de madera. «Es milagroso, y, en todo caso, nosotras se lo guardaremos a Otilia mejor de lo que usted puede hacerlo». «¿Milagroso?» les digo, «pues aquí se le olvidaron los milagros», y les regalo el San Antonio de madera, «pueden llevárselo cuando quieran». (2010: 134)

El concepto de nación unida en torno a un símbolo religioso integrador aparece en un contexto fuertemente irónico: cuando uno de los grupos armados ataca el pueblo y se lleva a varios vecinos para matarlos, el cura «[...] nos anuncia que el Divino Niño ha sido nombrado esta mañana figura religiosa nacional, que nuestro país sigue consagrado al Niño Jesús, oremos, insiste, pero, de hecho, ni él ora ni nadie parece dispuesto a corresponder con una oración» (Rosero, 2010: 94). La actitud de Ismael 
pone de manifiesto el carácter disruptivo de su experiencia, la imposibilidad de incluirla en los discursos existentes y la insuficiencia del lenguaje simbólico existente, subrayando la literalidad del trauma de la cual habla Caruth (1995b: 153).

El último aspecto de la subjetividad narrativa de Los ejércitos que cabe señalar se refiere a la interpretación y (finalmente) cuestionamiento de la guerra misma. Desde el principio, cuando en el primer capítulo se narra el atentado en la iglesia, ni el protagonista ni otros personajes saben quiénes son aquellos que atacan el pueblo. A lo largo del texto las isotopías indican, consecuentemente, no solo ignorancia, sino también indiferencia:

[...] no cumplía todavía los veinte años cuando lo mató, en una esquina, una bala perdida, sin que se supiera quién, de dónde, cómo. (Rosero, 2010: 32)

Yo no sabía todavía quiénes eran, si guerrilla, si paras. Ni les pregunté. (2010: 47)

«Fue uno que se llevaron», comentan los parroquianos, ¿a quién se llevaron esta vez?, nadie lo sabe, y tampoco nadie se muere por averiguarlo; que se lleven a alguien es un asunto común y corriente, pero resulta delicado averiguar demasiado, preocuparse en exceso. (2010: 65)

Me dicen que encontraron en su hacienda todas sus vacas degolladas. Algún disgusto les debió dar, pero a quiénes. (2010: 68)

No es posible descubrir si son soldados - o quiénes, si de acá, de allá, o del otro lado, ¿importa eso?. (2010: 10) ${ }^{3}$

La acumulación de palabras que expresan ignorancia, las preguntas retóricas, el uso y abuso de pronombres y adjetivos indeterminados dotan la novela de cierta borrosidad, le quitan descriptividad y hacen que el conflicto armado se perciba en su esencia, fuera de sus determinantes políticos, militares e ideológicos. Observa el protagonista: «Es extraordinario; parecemos sitiados por un ejército invisible y por eso mismo más eficaz» (Roseo, 2010: 124). No obstante, al final Ismael Pasos, con una ironía amarga, llega a cuestionar la guerra misma:

Si vemos menos soldados, de eso no se nos informa de manera oficial; la única declaración de las autoridades es que todo está bajo control; lo oímos en los noticieros —en las pequeñas radios de pila, porque seguimos sin electricidad-, lo leemos en los periódicos atrasados; el presidente afirma que aquí no pasa nada, ni aquí ni en el país hay guerra; según él Otilia no ha desaparecido, y Mauricio Rey, el médico Orduz, Sultana y Fanny la portera y tantos otros de este pueblo murieron de viejos, y vuelvo a reír, ¿por qué me da por reír justamente cuando descubro que lo único que quiero es dormir sin despertarme? Se trata del miedo, este miedo, este país, que prefiero ignorar de cuajo, haciéndome el idiota conmigo mismo, para seguir vivo, o con las ganas aparentes de seguir vivo, porque es muy posible, realmente, que esté muerto, me digo, y bien muerto en el infierno, y vuelvo a reír. (Rosero, 2010: 161)

En esta constatación del protagonista — que hasta cierto punto puede servir de conclusión de la novela entera- no solo se ve la actitud irónica del profesor Ismael Pasos, sino sobre todo resalta algo que se puede calificar como ironía de segundo

\footnotetext{
${ }^{3}$ En este caso, la cursiva de los fragmentos citados es de la autora del artículo.
} 
grado: al retomar el discurso oficial sobre la guerra en Colombia, tras seguir durante varios capítulos el relato enfocado desde la subjetividad del protagonista, lo vemos cuestionado, puesto en ridículo. Es en esto donde reside la gran fuerza expresiva de la estrategia narrativa adoptada por Rosero. Sirvan de conclusión las acertadas palabras de Padilla Chasing (2012: 148):

Al ubicar al lector en la conciencia de Ismael Pasos, el autor dota su novela de una dimensión fenoménica que le permite captar la esencia del conflicto armado en Colombia, es decir, la manera como se relaciona con la subjetividad. [...] Al renunciar a puntos de vista y estrategias narrativas que crean la ilusión de objetividad, buscando desaparecer del relato, Rosero logra representar, de primera mano, sin detenerse en el carácter síquico del asunto, no tanto la situación de un pueblo en el fuego cruzado de varios «ejércitos», sino las impresiones que la barbarie deja en la conciencia de sus habitantes.

\section{CONCLUSIÓN}

Lejos de agotar el tema de la narración del trauma y la violencia en la narrativa hispanoamericana reciente, el presente estudio muestra cómo la novela asume y absorbe las experiencias trágicas del pueblo y cómo convierte el trauma en literatura. Hemos presentado dos estrategias distintas a la hora de convertir un trauma en literatura: la autoficcional y la de una subjetividad extrema. El análisis de los textos demuestra que la producción artística de los novelistas armoniza con las observaciones de Caruth y LaCapra sobre la indecibilidad del trauma. El trauma se escapa de los discursos y modelos narrativos existentes; el resultado son relatos perturbados, mutilados y a la vez perturbadores que se autocuestionan constantemente. En los tres casos, los autores se alejan de la descripción, de la denuncia directa, del testimonio como núcleo de las obras. En cambio, exploran terrenos autoficcionales y metadiscursivos, reflexionando sobre la (im)posibilidad de denunciar la(s) violencia(s) y de curar traumas a través de la literatura, e indagando no solo en los discursos oficiales sobre la memoria histórica, sino también en la capacidad y las consecuencias de asumir traumas ajenos y transformarlos en materia literaria.

\section{BIBLIOGRAFÍA}

CARuth, C. (1995a). I. Trauma and Experience: Introduction. En C. Caruth (ed.), Trauma: Explorations in Memory (págs. 3-12). Baltimore: John Hopkins University Press.

- (1995b). II. Recapturing the Past: Introduction. En C. Caruth (ed.), Trauma: Explorations in Memory (págs. 151-157). Baltimore: John Hopkins University Press.

Castellanos Moya, H. (2005). Insensatez. Barcelona: Tusquets.

JosSA, E. (2013). Transparencia y opacidad: escritura y memoria en Insensatez de H. Castellanos Moya y El material humano de R. Rey Rosa. Centroamericana, 23/2, 31-58. 
LACAPRA, D. (2001). Writing History, Writing Trauma. Baltimore: John Hopkins University Press.

- (2008). Representar el Holocausto. Buenos Aires: Prometeo Libros.

Laub, D. (1995). Truth and Testimony: The Process and the Struggle. En C. Caruth (ed.), Trauma: Explorations in Memory (págs. 61-75). Baltimore: John Hopkins University Press.

Ortiz Wallner, A. (2012). El arte de ficcionar: la novela contemporánea en Centroamérica. Madrid / Frankfurt am Main: Iberoamericana-Vervuert.

Padilla Chasing, I.V. (2012). Los ejércitos: Novela del miedo, la incertidumbre y la desesperanza. Literatura: teoría, historia y crítica, 14, 121-158.

Rey Rosa, R. (2009). El material humano. Barcelona: Anagrama.

ROSERO, E. (2010). Los ejércitos. Barcelona: Tusquets.

Valencia Solanilla, C. (2007). Contrapunto y expresividad en Los ejércitos de Evelio Rosero. Poligramas, 28, 297-300. 